\title{
Water Transparency As One As Of Trophic State Indices In Narta Lagoon
}

\author{
Veledin Çako ${ }^{1}$, Eriola Zhuri ${ }^{2}$, Fatbardha Babani ${ }^{3}$, Theodhor Karaja ${ }^{4}$ \\ ${ }^{1}$ Department of Physics, Faculty of Technical Sciences, University of Vlora 'Ismail Qemali', Albania. \\ ${ }^{2}$ University of Durresi 'Aleksander Moisiu', Albania \\ ${ }^{3}$ Department of Biotechnology, Faculty of Natural Sciences, University of Tirana, Albania \\ ${ }^{4}$ Department of Physics, Faculty of Natural Sciences, University of Tirana, Albania
}

\begin{abstract}
Narta Lagoon, one of the largest and most important coastal ecosystems of Albania, is situated on the south-eastern coast of the Adriatic Sea, northwestern part of Vlora district. Water transparency that indicates the level of biological activity can be measured easily using a Secchi disc (Horizontal black disc). Horizontal Secchi disk was applied to measure the Secchi distance in Narta lagoon as a shallow one. The distance at which the disc disappears is recorded as the measure of water visibility. Turbidity which expresses the degree to which light is scattered and absorbed by molecules and particles, is a measure of the degree of the water transparency losing by the presence of suspended particulates including sediments and phytoplankton. Water turbidity is measured in FTU (Formazin Turbidity Units) applying a turbidimeter, type HANNA HI 93703-11.

Turbidity parameters are measured every two weeks over a sampling period from March to October 2012, at each of four selected sites differentiated by sea-lagoon water communication. Turbidity and transparency values of the sites varied noticeably exhibiting spatial differences by station as well as changes over the sampling period. The observed variations can be explain by the communication sea-lagoon, fresh water supply as well as by the pollution near the urban areas. Analysis of variance (one-way ANOVA) detected significant sites effect at Narta ecosystem $(\mathrm{P}<0.01)$. Water transparency recorded as Secchi distance and turbidity measured in FTU were strongly correlated taken in consideration all selected sites over the sampling period. The relationship between these parameters can be expressed by an inverse power trendline, $\mathrm{R}^{2}=0.94$. Classification of Hakanson and Carlson related to the Secchi distance measurements as bioindicator of algal abundance allowed to characterize the selected sites of Narta lagoon by different level of trophic state
\end{abstract}

Keywords: - Narta Lagoon, Secchi disk, Transparency, trophic state, turbidity, turbidimeter, water ecosystem.

\section{INTRODUCTION}

Trophic status of the water bodies could be classified on base of four indices (water clarity, chlorophyll $a$, total phosphorus and total nitrogen) which can be used as indicators to measure "biological productivity" of a water body or capacity to support life (Carlson, 1977; Hakanson, 2007).

Transparency of water, which indicates the concentration of dissolved and particulate material in the water, can be used to estimate the level of biological activity in a waterbody. Transparency decreases as algal abundance and/or suspended sediments increases. Measuring the clarity of water-which can be affected by soil erosion, runoff from urban and agricultural areas, wastewater and strom water inputs, alga and plant materials, and abundant bottom feeders stirring up sediment is important in evaluation of trophic state at aquatic ecosystems (J.A. HambrookBerkman \& M.G Canova, 2007).

Transparency as a measure of water clarity can be used for trend analysis in a waterbody, for location of differences in transparency within a waterbody, and to compare waterbodies. If, the measurement of other variables such as chlorophyll and total phosphorus are included, important information on the relationships between these trophic state variables can be provided. Transparency can be measured easily applying a Secchi disc that has the advantages of integrating turbidity over depth where variable turbidity layers are present (R.W. Preisendorfer, 1986; J.R. Zaneveld \& W.S. Pegau, 2004).

Turbidity as an optical property which describes the clarity of the water is a measure of the degree to which the water loses its transparency due to the presence of suspended particulates including sediments and phytoplankton. As turbidity measures the light scattering effect by suspended solids, the higher the intensity of scattered light results to the higher of the turbidity (EPA, 1999; G.C. Holdren, 2002). The suspended particles absorb heat from the sunlight, so turbid waters become warmer, and as a result reducing the concentration of oxygen in the water. The suspended particles also scatter the light, thus decreasing the photosynthetic activity of plants and algae contributing to low the oxygen concentration even more. Turbidity should be measured in the field. The most reliable method of determination are based on nephelometry (the property of light scattering by suspended particles) using a turbidity meter (E.A. Steel \& S.Neuhauser, 1999). 
Transparency and turbidity of the water are related to the type and concentration of suspended matter in the waterbody. These can be silt, clay, fine particles of organic and inorganic matter, soluble organic compounds, plankton and other microscopic organisms (approx. $10 \mathrm{~nm}$ to $0.1 \mathrm{~mm}$ in diameter) (D. Chapman \& V. Kimstach, 1996). Turbidity is related to the scattering and absorption of incident light by the particles, whereas the transparency is the limit of visibility in the water. Both can vary seasonally according to biological activity in a waterbody. Scattering of light from a certain amount of particulates is related to their properties as shape, color, and reflectivity. Also, heavier particles precipitate quickly and do not contribute to a turbidity reading. Turbidity, for these reasons, can be related to TSS and sometimes can be used as a indirect measurement for TSS being rather unique for each location or situation (D. Chapman \& V. Kimstach, 1996).

"Trophic status" of water bodies can be classified into four categories from the lower to the higher level of the biological productivity: Oligotrophic (clear and blue water, with very low levels of nutrients and algae), Mesotrophic (slightly green water, still clear, moderate levels of nutrients and algae), Eutrophic (green and murky water, with higher amounts of nutrients and algae) and Hypertrophic (supersaturated in phosphorus and nitrogen, excessive phytoplankton growth, poor water clarity). Waterbody with extreme low trophic indices may also be considered hyperoligotrophic (L. Hakanson \& A.C Bryhn, 2008; L. Hakanson \& A.C Bryhn, 2008).

Another classification system, trophic State Indices (TSI) (R.E. Carlson, 1977) provided a single quantitative index to categorize waterbodies in range from 1 to 100 reflecting a continuum of "states". It is based on the amount of biological productivity occurring in the water applying three variables and their relationships: chlorophyll, Secchi distance, total phosphorus and nitrogen, that independently estimate algal biomass. The index is an effective method of classifying trophic status in different waterbodies. Ranges of trophic state index values are often grouped into trophic state classifications: Values less than 40 are associated with oligotrophy (low productivity); the range between 40 and 50 is usually associated with mesotrophy (moderate productivity); values greater than 50 are associated with eutrophy (high productivity) (L. Hakanson \& A.C Bryhn, 2008; L. Hakanson \& A.C Bryhn, 2008).

The aim of the presented paper was to characterize the water turbidity and to classify trophic status in Narta lagoon based on this bioindicator.

\section{MATERIAL AND METHODS}

Narta Lagoon

The Narta Lagoon is one of the most important lagoons of Albania. This is situated in the northern part of the Vlora Bay, about $3 \mathrm{~km}$ from Vlora City. Two islands are located in the south part of the lagoon. Narta Lagoon has a surface of $41.8 \mathrm{~km}^{2}$, the maximum depth is $1.5 \mathrm{~m}$ and the average depth $0.7 \mathrm{~m}$. About $1 / 3$ of its surface is used for salt extraction. Narta Lagoon is divided from the Adriatic Sea by the low hills of ZverneciTreporti and by a littoral cordon of about $8 \mathrm{~km}$ long and width of $100-1400 \mathrm{~m}$. The Narta Lagoon is connected to the Adriatic Sea by two artificial channels, the South and the North Channel, that realize water exchange process between the lagoon and the Adriatic Sea. The South Channel is $110 \mathrm{~m}$ long, $18 \mathrm{~m}$ wide, $1.67 \mathrm{~m}$ deep; the North Channel is $650 \mathrm{~m}$ long, $20 \mathrm{~m}$ wide and $0.54 \mathrm{~m}$ deep. Limniological regime of Narta Lagoon is determined by the hydrologic and climatic conditions of surrounding area and the water exchange degree with the Adriatic Sea. At the same time a shallow zone forms a barrier in the middle south-western part. Water evaporation of the Narta Lagoon has a greatly increased during the summers, with high temperatures; the water exchange between sea and lagoon is decreased; the flow from the affluent basin is practically zero and the rainfall is almost completely absent. Under such conditions, the quantity of the water evaporating causes a great increase of the average salt concentration. The gradient of this change is increased in the relation to the distance from the lagoon inlets. During the winter the effect produced by the evaporation and the effect of drainage basin determine water shortage.

Four sampling stations were chosen in Narta lagoon:

Station $1-\mathrm{N} 40^{\circ} 33^{\prime} 46.6^{\prime \prime}$; E $019^{\circ} 26^{\prime} 70.0^{\prime \prime}$ : is located near the embankment between the lagoon and the Salinas of Skrofotina; is the nearest site to the northern communication channel with the sea.

Station $2-\mathrm{N} 41^{\circ} 47^{\prime} 10.1^{\prime \prime}$; E $019^{\circ} 36^{\prime} 31.4^{\prime \prime}$ : is located near embankment between the lagoon and salt mine, situated on the east of station 1 .

Station $3-\mathrm{N} 40^{\circ} 30^{\prime} 57.5^{\prime \prime}$; E $019^{\circ} 25^{\prime} 36.7^{\prime \prime}$ : is located near the Treporte; near the sourthern communication channel with the sea.

Station $4-\mathrm{N} 40^{\circ} 31^{\prime} 05.6^{\prime \prime}$; $019^{\circ} 24^{\prime} 20.5^{\prime \prime}$ : this site is near the island of Zvernec, positionated near the bridge.

\section{Horizontal black disc}

Horizontal black discs are devices for measuring underwater visibility in shallow waters where traditional vertical Secchi discs are impractical. In shallow waters of Narta lagoon where the Secchi disk can 
still be seen on the bottom and cannot be used, the horizontal disk is applied to measure the turbidity (R.W. Preisendorfer, 1986; J.R. Zaneveld \& W.S. Pegau, 2004). The horizontal black disc developed by (DaviesColley, R.J. 1988) consists of a black disc on a stick and a periscope, sealed with thick, clear, and plastic on one end. The disc and the covered end of the periscope are placed close together underwater, and then pulled apart until the disc is no longer visible through the periscope. The distance at which the disc disappears, and just reappears, is recorded as the measure of visibility. Because the black disc does not reflect light (ideally), this measure of visibility allows one to estimate the beam attenuation coefficient, an inherent property of light. Light attenuation by suspended matter has two main types of biotic effect: reduced light penetration into water for photosynthesis (Kirk, J. T. O., 1994), and reduced visual range of sighted organisms.

Two aspects of water clarity, light penetration and visual clarity, are both strongly affected by suspended matter in water and both are related to the optical properties of water. (Davies-Colley, R.J. 1988). Discussion of these two concepts and their relationship to turbidity and to suspended sediment has a great importance.

\section{TURBIDITY OF WATER}

Turbidity of water is measured in FTU (Formazin Turbidity Units) which is the most widely used measurement unit for turbidity applying a portable turbidimeter type HANNA HI 93703-11. The device measures the intensity of light scattered at 90 degrees as a beam of light passes through a water sample. The method is based upon a comparison of the intensity of light scattered by the sample under defined conditions with the intensity of light scattered by a standard reference suspension (Instruction Manual HI93703-11). HI 93703-11 turbidity meter is a portable, microprocessor-based instrument used to determine the turbidity of water and wastewater. The meter covers a 0 to 1000FTU range in two scales: 0.00-50.00and 50-1000. HI 93703-11 has been designed according to the ISO7027 International Standard.HANNA instruments use the primary standard AMCO-AEPA-1 to avoid all formazine-related problems as a very toxic, unstable substance. Hanna Instruments standards are extremely stable, can be reused, and last up to six months, if free from contamination. The instrument functions by passing a beam ofinfrared light through a vial containing the sample being measured. The light source is a High Emission Infrared LED (wavelength 890nm), ensuring that the interference caused by colored samples is minimum. A sensor, positioned at $90^{\circ}$ with respect to the direction of light, detects the amount of light scattered by the undissolved particles present in the sample. The microprocessor converts such readings into FTU values.

The water turbidity parameters (turbidity and visual clarity) were measured every one or two weeks at all selected sites in Narta lagoon from March to October (2012).

\section{CHLOROPHYLL CONTENT}

Content of chlorophyll $a$ was determined according to the acetone trichromatic method using the equations based on the absorption maxima for each component respectively, chlorophyll $a, b, c$ (with coefficients of Jeffrey \& Humphrey). All absorbance values are corrected taking in consideration the turbidity of acetone extracts (Jarry V., Frisoni G. F. \& Legendre P., 1991; Jeffrey S. W., Humphrey G. F., 1975; Lorenzen C. J., 1967; Ston, J. \&Kosakowska, A., 2000).

\section{Calculation of the TSI (SD)}

Carlson's index uses a log transformation of Secchi disk values as a measure of algal biomass on a scale from 0-110. Each increase of ten units on the scale represents a doubling of algal biomass. Values of the Carlson Trophic State Index for Secchi disk TSI (SD) and chlorophyll content TSI (Chl) were calculated by the formulas: TSI $(\mathrm{SD})=60-14.41 \ln (\mathrm{SD})$, where SD represents Secchi depth in meters; TSI $(\mathrm{Chl})=9.81 \ln (\mathrm{Chl})$ +30.6 , where Chl represents chlorophyll $a$ content in $\mathrm{mg} \mathrm{m}^{-3}$ (R.E. Carlson, 1977; R.E Carlson \& J.Simpson, 1996).

The Carlson trophic state index is used for comparing the selected sites in Narta lagoon and to assess changes in trophic status over monitoring time.

\section{Evaluation of trophic status}

Trophic status evaluation was based on the Hakanson and Carlson classifications related to the Secchi distance and chlorophyll content measurements as well as Carlson's index calculated on Secchi disk distance and content of chlorophyll (L. Hakanson and A.C Bryhn, 2008; R.E. Carlson, 1977; R.E Carlson \& J.Simpson, 1996)(Tab. 1, 2). 
Table 1.Trophic status based on chlorophyll (Chl), phosphorus (P) and Secchi distance (SD) (L. Hakanson \& A.C Bryhn, 2008).

\begin{tabular}{|c|c|c|c|}
\hline Trophic status & $\begin{array}{c}\text { SD } \\
(\mathrm{m})\end{array}$ & $\begin{array}{c}\text { Chl a } \\
\left(\mathrm{mg} \mathrm{m}^{-3}\right)\end{array}$ & $\begin{array}{c}\text { Total P } \\
\left(\mathrm{mg} \mathrm{m}^{-3}\right)\end{array}$ \\
\hline Oligotrophic & $>8-4$ & $0-2.5$ & $0-10$ \\
\hline Mesotrophic & $4-2$ & $2.5-8$ & $10-30$ \\
\hline Eutrophic & $2-0.5$ & $8-20$ & $30-90$ \\
\hline Hypereutrophic & $<0.5$ & $>20$ & $>90$ \\
\hline
\end{tabular}

Table 2.Relationships between Trophic Index (TI), chlorophyll (Chl), phosphorus (P, micrograms per litre), Secchi depth (SD, metres) and Trophic status (OECD, 1982).

\begin{tabular}{|c|c|c|c|c|l|}
\hline TSI & Chl & P & SD (m) & Trophic Class & \multicolumn{1}{|c|}{ Attributes } \\
\hline$<\mathbf{3 0}$ & $0-0.95$ & $0-6$ & $>8$ & Oligotrophic & $\begin{array}{l}\text { Clear water; high DO throughout the } \\
\text { year in the entire hypolimnion }\end{array}$ \\
\hline$<\mathbf{3 0 - 4 0}$ & $0-2.6$ & $0-12$ & $8-4$ & Oligotrophic & $\begin{array}{l}\text { Clear water; possible periods of limited } \\
\text { hypolimnetic anoxia. }\end{array}$ \\
\hline $\mathbf{4 0 - 5 0}$ & $2.6-7.3$ & $12-24$ & $4-2$ & Mesotrophic & $\begin{array}{l}\text { Water moderately clear; increasing } \\
\text { probability of hypolimnetic anoxia on } \\
\text { summer. }\end{array}$ \\
\hline $\mathbf{5 0 - 6 0}$ & $7.3-20$ & $24-48$ & $2-1$ & $\begin{array}{c}\text { Eutrophic } \\
\text { (Mild) }\end{array}$ & $\begin{array}{l}\text { Anoxic hypolimnia, macrophyte } \\
\text { problems possible. }\end{array}$ \\
\hline $\mathbf{6 0 - 7 0}$ & $20-56$ & $48-96$ & $1-0.5$ & $\begin{array}{c}\text { Eutrophic } \\
\text { Blue-green algae dominate, algal scums } \\
\text { and macrophyte problems }\end{array}$ \\
\hline $\mathbf{7 0 - 1 0 0 +}$ & $56-155+$ & $96-384+$ & $0.5-<0.25$ & $\begin{array}{c}\text { Hypereutrophi } \\
\text { c }\end{array}$ & $\begin{array}{l}\text { Light limited productivity. Dense algae } \\
\text { and macrophytes. }\end{array}$ \\
\hline
\end{tabular}

\section{Statistical analysis}

Correlation analyses and multiple regression analyses were used to describe the relationships between the variables of interest (Secchi depth and turbidity) in different stations. Analysis of variance (one-way ANOVA) was used to test for differences between sites and sampling periods.

\section{RESULTS AND DISCUSSION}

\section{Turbidity of water}

Turbidity values of the Narta lagoon measured by the turbidimeter ranged from 0.28 to 16.92 FTU; the lowest value was measured at Station 1 on October whereas the highest one was measured at Station 4 on midApril (Fig. 2). The dynamics of water turbidity on selected stations in Narta lagoon showed the same variations during the monitoring period March - October (Fig. 2).

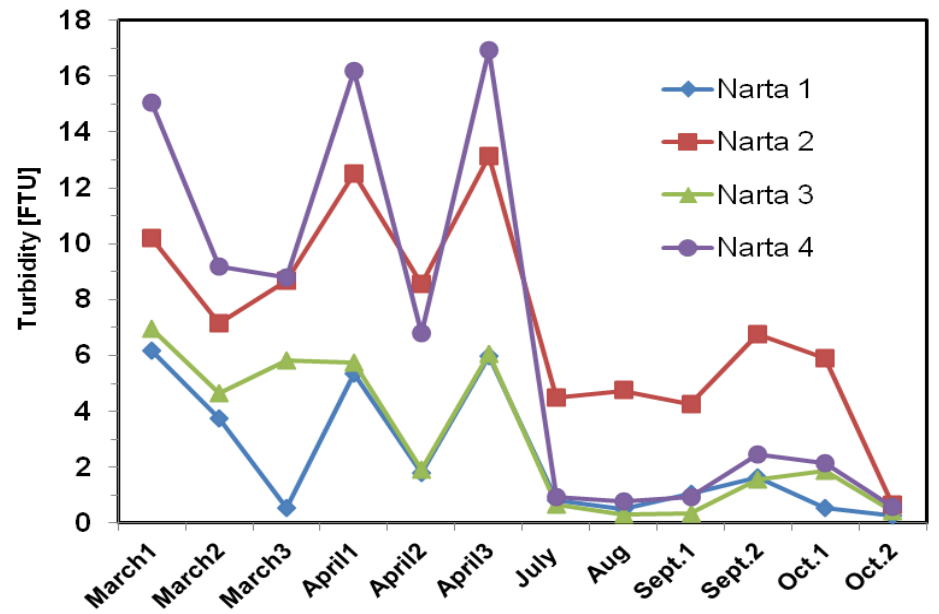

Figure 2. Variation of turbidity in Narta lagoon during monitoring period. 
During monitoring period from March to April the water turbidity of station 4 represented much higher values than of three other stations. Water turbidity of station 1 and station 3 in Narta lagoon showed very low values during monitoring period demonstrated the highest values on beginning of March and end of April respectively (Fig. 2). These stations were characterized by a good communication with the sea, especially station 3 that was very close to the sea-lagoon channel of communication. Values of water turbidity were increased from July showing the highest value on mid September; after that, the water turbidity was reduced up to very low values on October. The water turbidity of station 2 represented much higher values than those at other stations through the monitoring period July-October. Higher values of turbidity could be explained by the communication of this station with the sea (it was situated at the larger distance to the communication channel compare to the other stations) and the high level of pollution during the summer.

The average values of water turbidity taking in consideration measured values during monitoring period demonstrated than turbidity of station 2 in Narta lagoon was higher than turbidity of three other stations (Tab. 2).

Table 2.Turbidity of water of Nartaecosystem.

\begin{tabular}{|c|c|}
\hline Narta lagoon & Turbidity of water (FTU) \\
\hline Station 1 & 2.36 \\
\hline Station 2 & 6.71 \\
\hline Station 3 & 3.03 \\
\hline Station 4 & 6.53 \\
\hline Mean & $\mathbf{4 . 6 5}$ \\
\hline
\end{tabular}

Single-factor analysis of variance (one-way ANOVA) detected significant sites effect: Significant differences between station 2 and three other stations at Narta lagoon $(\mathrm{P}<0.01)$ but no significant differences among these three stations (St. 1, St. 3 and St. 4).

\section{Secchi disk distance}

Secchi distance values of the Narta lagoon measured by the horizontal Black disk ranged from 0.7 to $4.7 \mathrm{~m}$; the lowest value was measured at Station 4 on mid-April whereas the highest one was measured at Station 4 on October (Fig. 3). Water transparency (Secchi distance) of station 1, station 3 and station 4 at Narta lagoon demonstrated higher values on August. After that, the water transparency of these stations is decreased up to end of September-beginning of October and later was increased continuously up to mid of October, obtained maximum values of transparency (Figure. 3). Stations 1 and 3 were characterized by a good connection to the sea, especially station 3 which was nearer to the sea-lagoon communication channel.

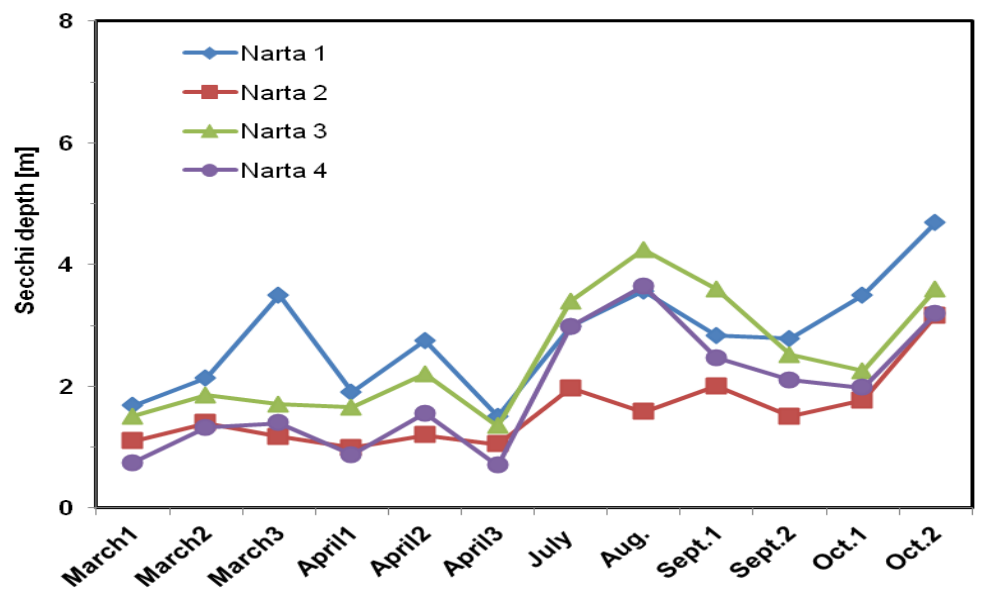

Figure 3.Variation of Secchi depth in Narta lagoon during monitoring period.

Water transparency of station 2 of Narta lagoon demonstrated also the highest value on July. After that, the water transparency is decreased on August and later was increased on the beginning of September, but was reduced again on the mid-September but afterward was also increased continuously up to the maximum values of transparency on the mid-October (Figure. 3). The monitored water transparency of this station at Narta 
lagoon presented lower values than other stations. This could be explained to a bad connection of station 2 to the sea as well as to a higher pollution than other stations.

The mean values of water transparency taking in consideration measured values during monitoring period demonstrated than average transparency of station 2 in Narta lagoon $(1.59 \mathrm{~m})$ was considerably lower than three other stations (St.1 - 2.84m; St.3 - 2.57m, St.4 - 2.12m).

Variance analysis by one-way ANOVA detected significant sites effect at this ecosystem: Significant differences between station 2 and three other stations at Narta lagoon $(\mathrm{P}<0.01)$ but not among these three stations (St. 1, St. 3, St. 4).

\section{Turbidity and Secchi depth relationship}

Secchi disk transparency and turbidity are strongly correlated taken in consideration all selected sites over the sampling period. The relationship between these parameters, distance of the viewing Secchi disk and turbidity, can be expressed by an inverse power function $\left(y=a x^{-b}\right)$ that is characterized by a negative correlation (Fig. 4).

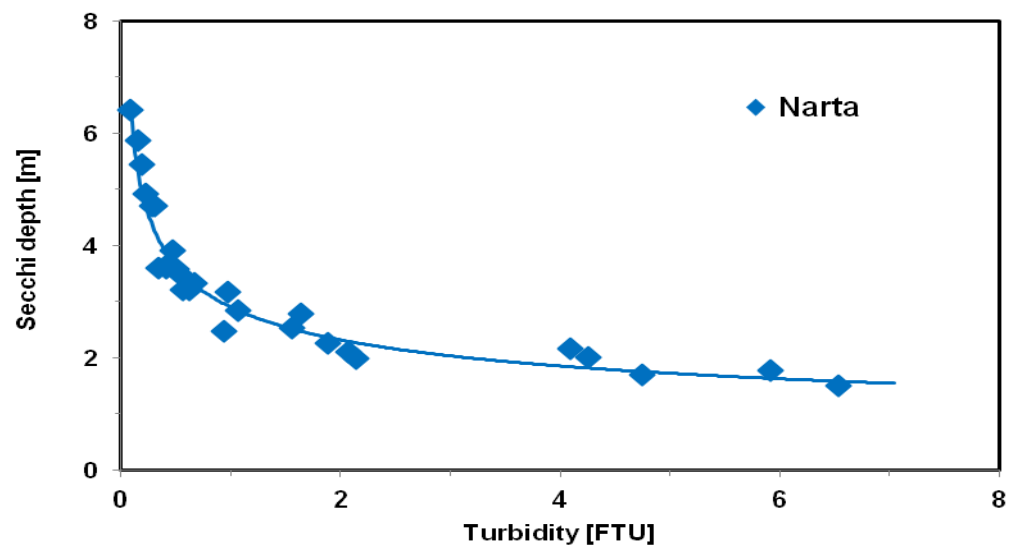

Figure 4. Relationship between turbidity and the depth of the viewing disk in Narta lagoon (inverse power function $\left.\mathrm{R}^{2}=0.94\right)$.

Based on all the data of the measurements performed in Narta lagoon, the equation of the power function can be described by the values of parameters as $\mathrm{a}=2.87, \mathrm{~b}=0.36$, and high correlation displayed by the value $\mathrm{R}^{2}=$ 0.94 (Fig. 4).

Variability of turbidity and transparency in monitored stations as well as their differences are quite exhibited by comparison the scale of these parameters on graphic representation (Fig. 4).

\section{Chlorophyll Content}

Dynamics of Chla content of the selected stations demonstrated almost the same variation from April 1 to April 3 in Narta lagoon (Fig. 5). Chlorophyll content of Narta lagoon, station 2 and station 4, demonstrated the highest values on April 1. After that, the Chl content is decreased on April 2 and then is increased on April 3.Chlorophyll content of station 1and station 3 of Narta lagoon demonstrated the lowest value on April 1. After that, the Chl content is decreased up to April 3. The Chl content of monitored station 1 and station 3 of Narta lagoon represent the lower values than two other stations. These two stations can be characterized by a good connection to the sea, especially station 3 which is located nearer to the communication sea-lagoon.

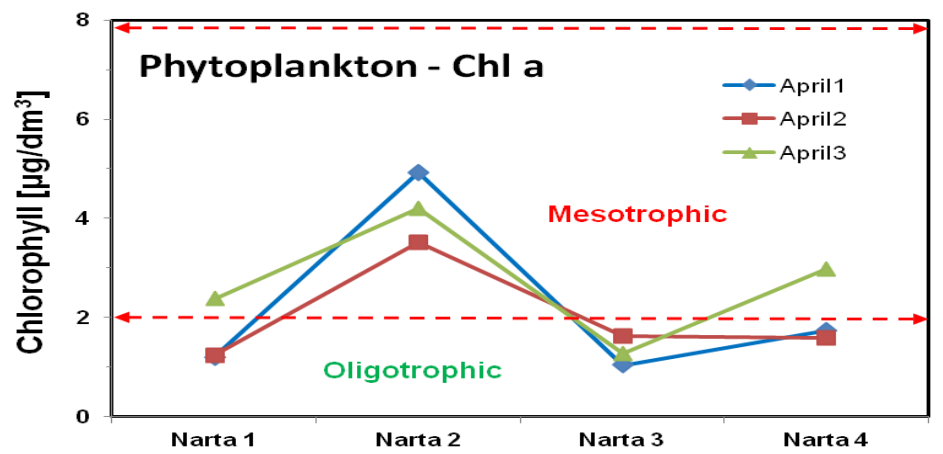

Figure 5.Dinamics of chlorophyll a content in Narta lagoon. 
Trophic state evaluation based on Secchi distance and Trophic state index TSI (SD)

The monitored water ecosystem of Narta lagoon can be characterized by different level of trophy based on the trophic state classification by Hakanson $(10,11)$ (Tab. 3, Fig. 6). Average values of Secchi distance of each sampling site over the sampling period allowed to classify the trofic status of all stations in Narta lagoon as mesotrophic, where the trophic status of station 2 is higher than the others.

Table 3. Trophic status by Secchidistance and Chl content of Narta lagoon.

\begin{tabular}{|c|c|c|c|c|c|c|}
\hline \multirow[t]{2}{*}{2012} & \multicolumn{3}{|c|}{ Trophic index } & \multicolumn{2}{|c|}{ Mean } & \multirow[t]{2}{*}{ Trophic status } \\
\hline & Station & $\mathbf{S D}(\mathrm{m})$ & Chl $\left(\mathrm{mg} / \mathrm{m}^{3}\right)$ & SD & Chl & \\
\hline \multirow{4}{*}{ 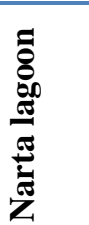 } & Narta 1 & 2.84 & 1.601 & \multirow[t]{4}{*}{2.28} & \multirow[t]{4}{*}{2.308} & \multirow[t]{4}{*}{ Mesotrophic } \\
\hline & Narta 2 & 1.59 & 4.216 & & & \\
\hline & Narta 3 & 2.57 & 1.315 & & & \\
\hline & Narta 4 & 2.12 & 2.101 & & & \\
\hline
\end{tabular}

Calculated values of trophic state index taken in consideration Secchi distance TSI (SD)and chlorophyll content TSI (Chl) and based on the Carlson trophic state classification (Tab. 4) $(10,11)$ exhibited that the trophic status of all stations in Narta lagoon could be evaluated as mesotrophic.

Table 4. TSI values of trophic state index taken in consideration Secchi distance and Chl content of Narta lagoon.

\begin{tabular}{|c|c|c|c|c|c|c|}
\hline \multirow[t]{2}{*}{2012} & \multicolumn{3}{|c|}{ Trophic index: } & \multicolumn{2}{|c|}{ Mean } & \multirow[t]{2}{*}{ Trophic status } \\
\hline & Station & TSI (SD) & TSI (Chl) & TSI (SD) & TSI (Chl) & \\
\hline \multirow{4}{*}{ 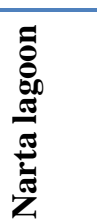 } & Narta 1 & 44.88 & 35.22 & \multirow[t]{4}{*}{49.24} & \multirow[t]{4}{*}{37.78} & \multirow{4}{*}{$\begin{array}{c}\text { Mesotrophic to } \\
\text { eutrophic }\end{array}$} \\
\hline & Narta 2 & 52.95 & 44.71 & & & \\
\hline & Narta 3 & 47.08 & 33.29 & & & \\
\hline & Narta 4 & 52.05 & 37.88 & & & \\
\hline
\end{tabular}

Calculated trophic state index taken in consideration Secchi distance TSI (SD) exhibited higher values than trophic state index taken in consideration chlorophyll content TSI (Chl) (TSI (SD) > TSI (CHL) showing that a non-algal particulates or color dominate light attenuation in water of Narta lagoon.

Relationship between turbidity and trophic state evaluated by other bioindicators.

In previous studies, trophic state of some waterbodies was evaluated based on chlorophyll a as bioindicator $(14,15)$. Narta lagoon was characterized by a mezotrophic status represented higher level in site 2 than other sampling sites, taking in consideration the mean values of Chl content of all selected stations over a period of two years.

The large number of criteria that have been used to determine trophic status has contributed to the contention that the trophic concept is multidimensional, involving aspects of nutrient loading, nutrient concentration and productivity. Consequently, trophic status could not be evaluated by examining one or two parameters but would be better all of them. It is suggested that for purposes of classification priority would be given to the biological parameters, especially the chlorophyll index during summer, and the phosphorus values. A reasonable estimation can be made through TSI values calculated on the base of all bioindicators as Secchi disk transparency, chlorophyll and total phosphorus that would result in about the same index value during any period of the year.

\section{CONCLUSIONS}

Turbidity and Secchi disk transparency exhibited high variability over the entire sampling period at each station and between stations in Narta ecosystem. Observed differences on turbidity/Secchi distance transparency through monitored sites showed highest values of turbidity/lowest values of transparency at station 2. 
Spatial differences by sites on turbidity/transparency level of the selected stations on Narta ecosystem were observed as well. These differences could be explained by the communication sea-lagoon, fresh water supply as well as by the pollution near the urban areas.

A possible negative correlation between the Secchi distance transparency and the water turbidity can be existed at Narta lagoon. The relationship can be expressed by an inverse power function and characterized by a high correlation as displayed by the values of $\mathrm{R}^{2}=0.94$.

Single-factor analysis of variance (one-way ANOVA) detected significant differences through different monitored sites $(\mathrm{P}<0.01)$ related to the turbidity and Secchi disk transparence too: Significant differences between station 2 and three other stations at Narta lagoon.

Classification of Hakanson and Carlson related to the Secchi distance measurements as bioindicator of algal abundance allowed to characterize the selected sites of monitored ecosystem by different level of trophic state: Narta lagoon could be evaluated as mesotrophic, showing spatial differences by stations.

\section{REFERENCES}

[1] EPA Guidance Manual Turbidity Provisions(1999), p 7/1- 7/6

[2] G.C. Holdren(2002).Turbidity and Other Sediment Surrogates Workshop.

[3] D. Chapman and V. Kimstach(1996). Water Quality Assessments, UNESCO/WHO/UNEP, pp79-82.

[4] E.A. Steel and S.Neuhauser(1999).RCSE-TRS No. 023.

[5] R.W. Preisendorfer(1986).Limnol.Oceanogr, 31, 909-926.

[6] J.R. Zaneveld and W.S. Pegau(2004).Opt. Express 11, 2997-3009.

[7] J.A. HambrookBerkman and M.G Canova(2007). U.S.G.S. Techniques of Water-Resources Investigations, book 9, chap. A7, section 7.4, p.17-20.

[8] L. Hakanson and A.C Bryhn(2008)., Eutrophication in the Baltic Sea, Pg 7.

[9] L. Hakanson and A.C Bryhn, Tools and Criteria for Sustainable Coastal, 19-22, 125-131 (2008)

[10] R.E. Carlson, Limnology and Oceanography, 22: 361-369 (1977)

[11] R.E Carlson and J.Simpson, A Coordinator's Guide to Volunteer Lake Monitoring Methods, 96 pp (1996)

[12] Instruction Manual HI93703-11. Portable Logging Turbidity Meter with RS232

[13] OECD, Eutrophication of waters: monitoring, assessment and control of Economic Cooperation and Development, pp154 (1982)

[14] F. Babani, Ecologia, conservazione e gestionedegliecosistemi di transizione e costieri. INTERREG IIIA AMJOWELS (2007)

[15] F. Babani, E. Kongjika, A. Mullaj, A. Ylli, Rivers and citizens: Cross-border experiences in environmental protection and sustainable development. 27-36p (2007)

[16] Davies-Colley, R.J. 1988. Measuring water clarity with a black disk.Limnol.And. Oceanogr. 33. 616-623.

[17] (17)Jarry V., Frisoni G. F. \& Legendre P., 1991: Spatial organization of a lagoon phytoplankton population under marine and continental influences. Oceanol.Acta, vol 14, No. 5, 473-488.

[18] Jeffrey S. W., Humphrey G. F., 1975: New spectrophotometric equation for determining chlorophyll a, b, c1 and c2. Biochem. Physiol. Pflanz., 167, 194-204.

[19] Lorenzen C. J., 1967: Determination of chlorophyll and phaeopigments: spectrophotometric equations, Limnol. Oceanogr., 12.

[20] Ston, J. \&Kosakowska, A., 2000: Qualitative and quantitative analysis of Baltic phytoplankton pigments. Oceanologia, 42, 449-471.

[21] Kirk, J. T. O., 1994. Light and Photosynthesis in Aquatic Ecosystems.(Second Edition).Cambridge University Press, New York, New York.509 pp. 